\title{
Grouping rice genotypes in different clusters based on their similarity index
}

\author{
Alia $^{1}$, Iftikhar Hussain Khalil ${ }^{2}$, Syed Mehar Ali Shah ${ }^{2}$, Durrishahwar ${ }^{3}$ \\ and Muhammad Noor $^{2 *}$ \\ 1. Agriculture Research Institute, Mingora Swat, Pakistan \\ 2. Department of Plant Breeding and Genetics, University of Agriculture, Peshawar, Pakistan \\ 3. Department of Plant Breeding and Genetics, University of Swabi, Pakistan \\ *Corresponding author's email: noor_pbg49@yahoo.com \\ Citation \\ Alia, Iftikhar Hussain Khalil, Syed Mehar Ali Shah, Durrishahwar and Muhammad Noor. Grouping rice genotypes \\ in different clusters based on their similarity index. Pure and Applied Biology. Vol. 5, Issue 3, pp386-391. \\ http://dx.doi.org/10.19045/bspab.2016.50050
}

\begin{tabular}{llll}
\hline \hline Received: 27/01/2016 & Revised: 14/04/2016 & Accepted: 20/04/2016 & Online First: 05/05/2016 \\
\hline
\end{tabular}

\section{Abstract}

The present study was carried out to characterize indigenous rice accessions on the basis of twentyfour qualitative and fourteen quantitative traits at the agriculture research area of Plant Breeding and Genetics, The University of Agriculture, Peshawar. Most of the morphological characters showed variation in different accessions except leaf sheath, internode color, ligule shape and auricle color. A significant amount of variation was displayed for most of the quantitative traits examined i.e, culm length, peduncle length, flag leaf length, panicle length, secondary branches penicle $^{-1}$ and spikelets penicle ${ }^{-1}$ whereas for other traits, relatively less variation was observed. On the basis of cluster analysis for qualitative traits, four clusters were identified at a dissimilarity level of 2.31. In cluster analysis or quantitative traits, three clusters were observed at dissimilarity level of 5.36. Five accessions exhibited superiority among all accession potential for most of traits and its genetic potential can exploited in future rice breeding programs.

Key words: Rice germplasm; Genotypic coefficient of variation; Dissimilarity index;

Agromorphological variation; Dendrogram

\section{Introduction}

Rice (Oryza sativa L.) is the world's most important cereal crop and serves as the primary source of staple food for more than half of the global population. The total area and production for rice crop exceeds all crops except wheat. Rice is planted on 155 million hectares with production of 5.5 million tones [1]. In Pakistan it is grown on an area of 2.52 million hectare. The total share of rice in value added and GDP is $6.1 \%$ and $1.3 \%$, respectively [1]. In NWFP rice is grown in two climatic conditions i.e Peshawar and D.I Khan [2].
There is a decline in genetic base and increase in genetic vulnerability of rice due to large scale replacement of traditional varieties with modern and high yielding varieties. There is a direful need to broaden the genetic base of rice by introgressing genes from diverse sources. Thus, there is a need to collect, exploit and evaluate the untapped germplasm. In this context, an attempt was made to characterize a set of rice germplasm accessions for different morphological and agronomic trials and to identify the variability available in the collection. The traits related to morphology and agronomy is 
the main source of studying classification and genetic variability among populations [3]. Accessions on desired morphological and agronomical traits can be selected for their onward utilization in rice breeding programs [4]. For this purpose the present experiment was conducted on morphological characterization, collected from different growing regions of Pakistan aimed to identify desirable genotypes for onward use in rice breeding program.

\section{Material and methods}

Plant material in the form of twenty four rice accessions, used in this study were collected from Northern Region of Pakistan by National Agriculture Research Center (NARC), Islamabad. Seedlings of these accessions were raised in pots in the screen house at The University of Agriculture Peshawar in the month of June, 2009. These seedlings were transplanted in a well puddled field at the research farm area of Plant Breeding and Genetics department. Each entry was sown in a single row of three meter length at spacing of $30 \mathrm{~cm}$ between rows and $20 \mathrm{~cm}$ between plants. The list of rice accessions used in the study is given in Table 1 .

Table 1. List of rice accessions used in the study at The University of Agriculture Peshawar

\begin{tabular}{l|l|l|l|l}
\hline Accession no & Accession no & Accession no & Accession no & Accession no \\
\hline Acc. 7637 & Acc. 7642 & Acc. 7647 & Acc. 7653 & Acc. 7664 \\
Acc. 7638 & Acc. 7643 & Acc. 7648 & Acc. 7654 & Acc. 7665 \\
Acc. 7639 & Acc. 7644 & Acc. 7649 & Acc. 7656 & Acc. 7667 \\
Acc. 7640 & Acc. 7645 & Acc. 7650 & Acc. 7657 & Acc. 7668 \\
Acc. 7641 & Acc. 7646 & Acc. 7652 & Acc. 7660 & \\
\hline
\end{tabular}

Data on morphological parameters were collected from flowering tillers of five plants of each entry at appropriate stage of growth to examine variation in twenty four qualitative (culm angle, blade pubescence, internode colour, blade colour, flag leaf angle, ligule color, ligule shape, auricle colour, collar colour, panicle type, basal leaf sheath color panicle exertion, awning, awn color, stigma color, anther color, panicle axis, flowering mounth, apiculs colour, sterile lemma colour, lemma and palea colour, lemma and palea pubescence, panical shattering and leaf sheath colour). Similarly fourteen quantitative traits including culm length $(\mathrm{cm})$, internode length $(\mathrm{cm})$, peduncle length $(\mathrm{cm})$, flag leaf length $(\mathrm{cm})$, flag leaf width $(\mathrm{cm})$, leaf length $(\mathrm{cm})$, leaf width $(\mathrm{cm})$, ligule length $(\mathrm{mm})$, panicle length $(\mathrm{cm})$, number of primary branches panicle ${ }^{-1}$, number of secondary branches panicle ${ }^{-1}$, number of spikelets panicle ${ }^{-1}$, awn length and anther length were also studied.
The data after compiling were statistically analyzed using the nested option of NTSYSpc $2.02 \mathrm{k}$ version. Mean values per accession were used and standardized prior to analyses. Pair wise Euclidean distance of the genotypes was computed for qualitative and quantitative traits.

\section{Results and discussion Qualitative traits}

The material displayed considerable variability for morphological traits except ligule shape, collar colour, internode colour, below flag leaf angle, ligule shape and auricle color. Two types of culm angle were observed erect and intermediate. Accessions number 7653, 7664, 7652, 7649, 7645, 7644, 7640, 7639, and 7637 showed intermediate culm angle, remaining rice genotypes was erect. Basal leaf sheath colour of all genotypes was green. Leaf angle of accession number 7638 was erect whereas rest of genotypes showed intermediate leaf angle. White ligule colour was showed by all the 
rice genotypes used in the study. Auricle color of all the genotypes used in the study was pale green colour. Two types of blade pubescent were observed, pubescent and intermediate pubescence. Blade colour of accession number 7638, 7642, 7645, 7654, $7665,7667,7668$ and 7657 were pale green and dark green color was also observed in Accession number 7653. Green color was manifested in the rest of the rice genotypes. Most of the genotypes started flowering in the month of September, but other genotypes flowering were started in October. All of the genotypes used in the study began to open spikelets and pollen shedding from 9:00 am onwards. All the three panicle types' intermediate, compact, open were observed in different rice genotypes. Variation was also observed among tested genotypes for panicle exsertion. Panicle axis of Accession number 7650, 7645, 7648, 7642, 7643 and 7638 were straight, rest of the Accessions displayed droopy panicle axis. Panicle shattering also showed variation of four types i.e. low, moderately high and high. A majority of genotypes were of moderate panicle shattering.

Awning and awn color traits varied among rice genotypes used in the study. Some genotypes were awn less and others were short and fully awned. Accessions number 7652, 7642, 7640, 7637 displayed purple awns remaining rice genotypes were manifested straw color. Apiculus colour of the rice genotypes were brown except Accession number 7653, 7650, 7649, 7648, $7646,7644,7645,7642$ and 7638 which gave white colour other accessions manifested purple colour. Stigma colour of majority of the rice genotypes was white colour stigma, except accessions number 7652, 7637, 7640 and 7642 which was purple colour. Most of accession were of pale yellow anther colour remaining were showed yellow anther colour. Variation was also observed for lemma and palea pubescence. Some genotypes showed glabrous lemma and palea. Accession number 7637, 7638, 7639, 7640 and 7641 showed hair on upper portion, whereas the remaining genotypes displayed short hairs on their entire lemma and palea. The majority of genotypes were showed sterile lemma and palea, whereas colour of sterile lemma and palea were red and straw colour, gold colour sterile lemma and palea were also observed. Lemma and palea color of accessions number 7653, 7650, 7641, 7640 and 7638 were observed brown spot on straw, gold and straw colour lemma and palea were also observed in the remaining genotypes. These results were compatible with the finding of $[5,6]$ who evaluated genotypes of rice for genetic variability. Genetic diversity in morphological traits had been reported previously by [7].

\section{Quantitative traits}

Marked variation was observed for culm length, peduncle length, flag leaf length, panicle length, secondary branches panicle ${ }^{-1}$ whereas for other traits, relatively less variation was observed (Figure. 1, 2 \& 3). Culm length among rice genotypes ranged from 79 to $130 \mathrm{~cm}$. Accession number 7664 displayed maximum culm length $(130 \mathrm{~cm})$ whereas acession number 7646 manifested minimum culm length $(79 \mathrm{~cm})$. Internode length among the genotypes ranged from 15 to $25 \mathrm{~cm}$. Peduncle length varied among the genotypes between 26 and $40 \mathrm{~cm}$. Maximum peduncle length was recorded for accession number $7668(40 \mathrm{~cm})$ followed by accession number 7664,7641 with peduncle length of 39 and $38 \mathrm{~cm}$, respectively. Our results of peduncle length were in consensus with [3]. Flag leaf length among the genotypes varied from 16 to $46 \mathrm{~cm}$, whereas range observed for flag leaf width was 0.9 to $1.8 \mathrm{~cm}$. Ligule length among the genotypes ranged from 1.1 to $2.3 \mathrm{~mm}$. Accession number 7642 gave maximum value $(2.3 \mathrm{~mm})$ for the trait whereas accession number 7641 and 7652 displayed minimum value $(1.1 \mathrm{~mm})$. 
Panicle length varied from 20 to $28 \mathrm{~cm}$, ranged of primary branches panicle ${ }^{-1}$ was from 7 to 12 . Accession number 7664 had maximum primary branches whereas, accession number 7645 had minimum number of secondary branches (Figure. 3). Number of spikelet panicle ${ }^{-1}$ among rice genotypes varied from 72 and 159. Awn length among rice genotypes under study varied from 0.7 to $6.0 \mathrm{~cm}$. Accession number
7643 and 7644 manifested minimum awn length of $0.7 \mathrm{~cm}, 7668$ had maximum awn length of $6.0 \mathrm{~cm}$. Awn length among the genotypes ranged from 1.6 to $2.0 \mathrm{~mm}$. Marked variation was observed in accession number 7639, 7665, 7649, 7652, 7667 and 7664 for culm length, internodes length, no of secondary branches panicle ${ }^{-1}$ and spikelet panicle $^{-1}$. The results are compatible to the previous results [7-9].

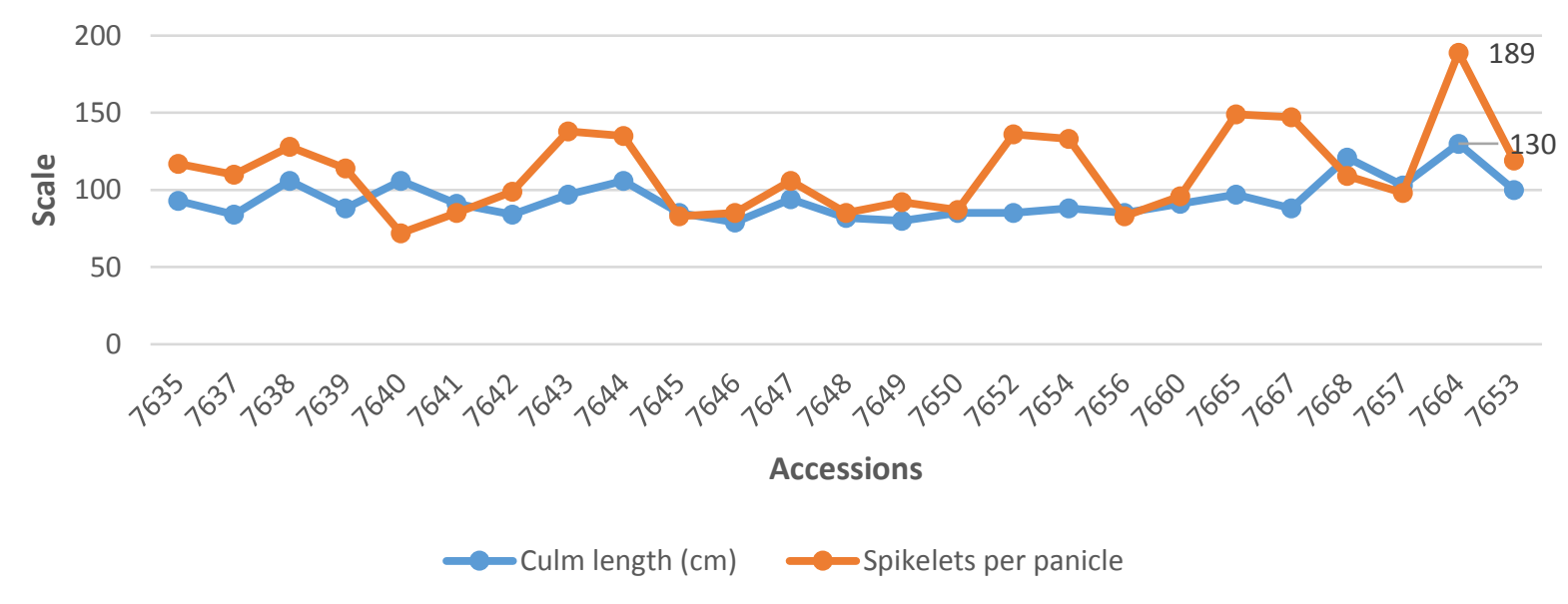

Figure 1. Means of rice accessions for culm length $(\mathrm{cm})$ and spikelets per panicle

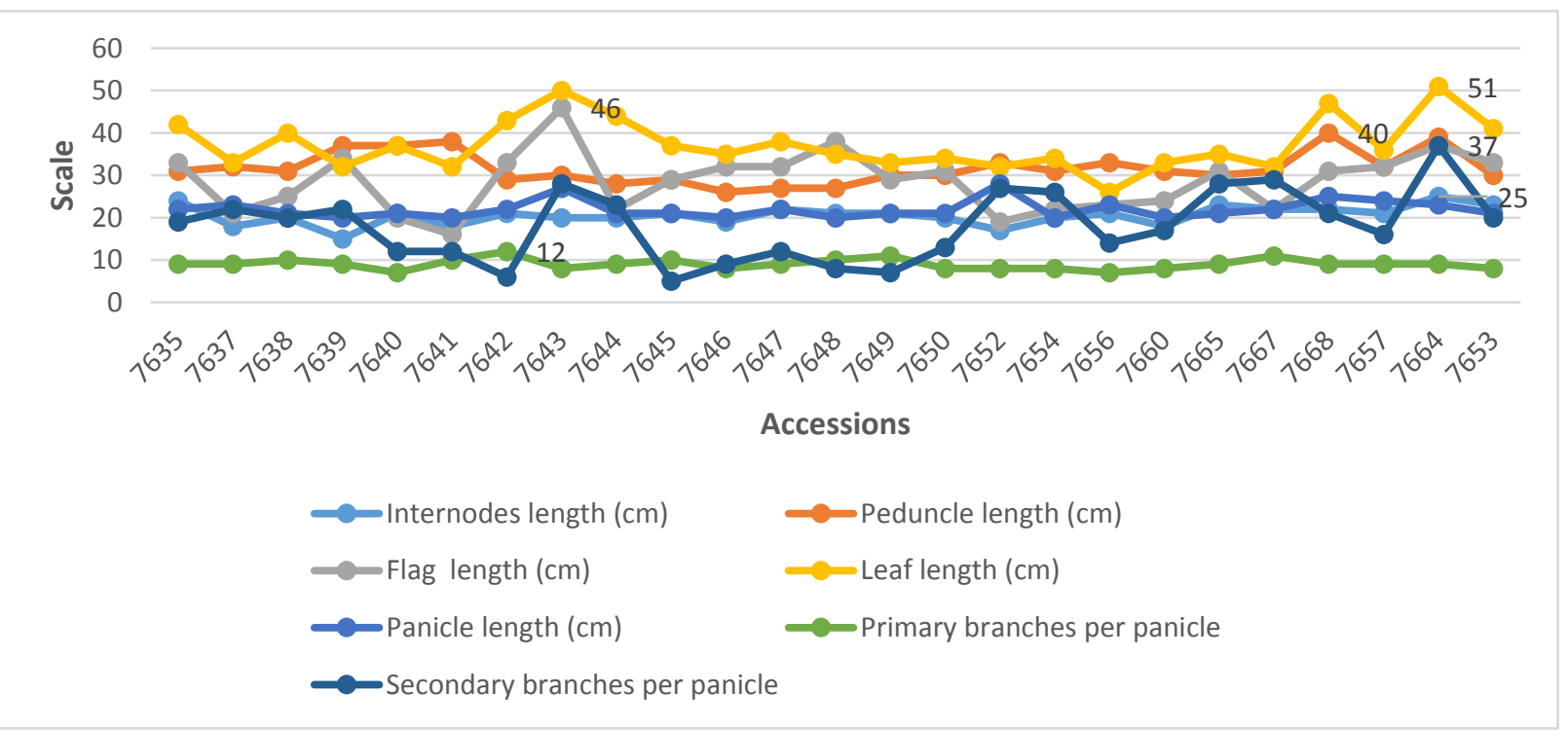

Figure 2. Means of rice accessions for internode length $(\mathrm{cm})$, peduncle length $(\mathrm{cm})$, flag leaf length $(\mathrm{cm})$, leaf length $(\mathrm{cm})$, panicle length $(\mathrm{cm})$, primary branches per panicle and secondary branches per panicle 


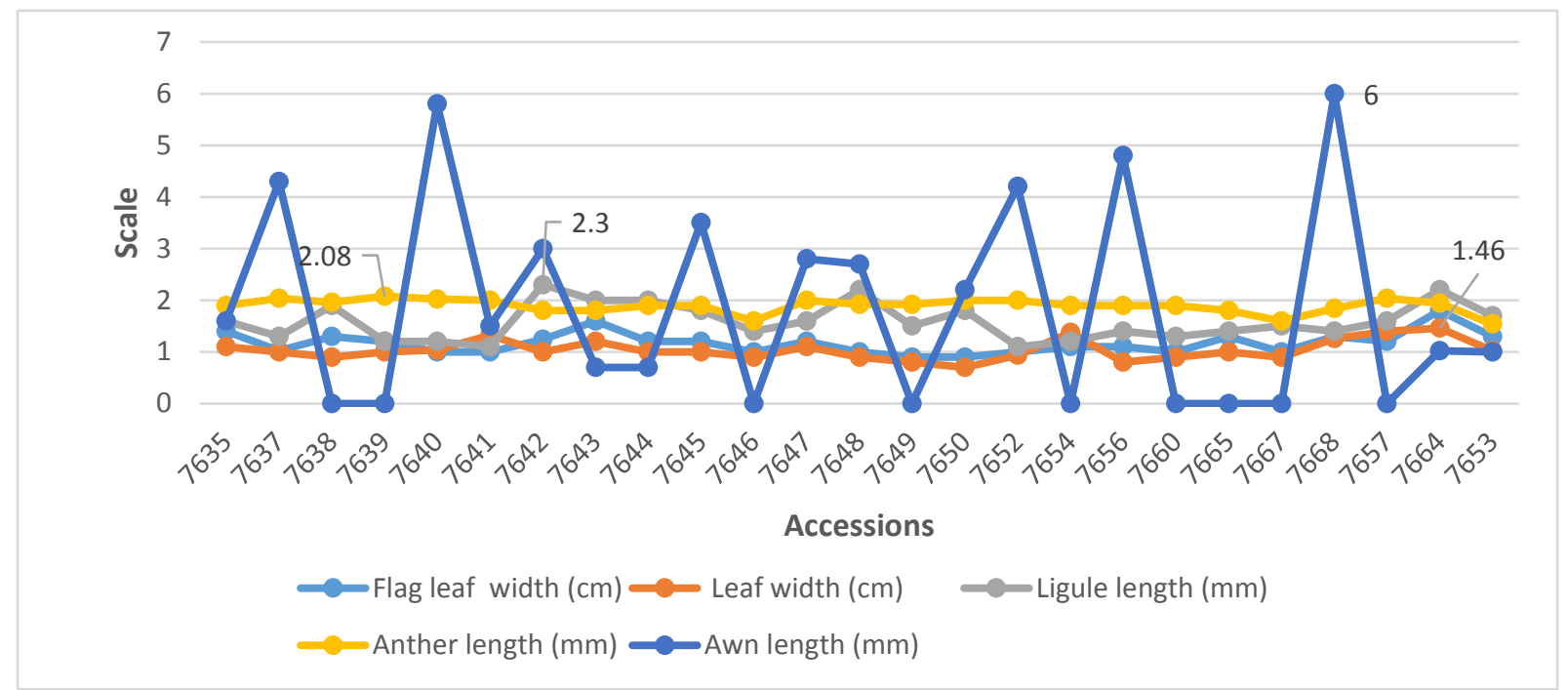

Figure 3. Means of rice accessions for flag leaf width $(\mathrm{cm})$, leaf width $(\mathrm{cm})$, ligule length $(\mathrm{mm})$, anther length $(\mathrm{mm})$ and awn length $(\mathrm{mm})$.

\section{Cluster analysis}

On the basis of cluster analysis for qualitative traits, four clusters can be identified at a dissimilarity level of 2.31 (Figure 4). The first cluster comprised 7637, 7652 and 7640, the second cluster was consisted of 7639 , 7642, and 7668 and the third cluster had 7638, 7667, 7660, 7653,7644, 7657, 7650, 7647, 7649, 7641, 7664, 7665,7643 and 7646. Fourth cluster was comprised of 7645 , 7648, 7654 and 7656.
In quantitative traits, three clusters were observed at a dissimilarity level of 5.36 (Figure 5). Accessions 7637, 7652, 7640, 7656, 7639, 7641, 7638, 7644, 7667, 7665, 7653, 7654, 7657, 7642, 7645, 7647, 7648, 7649,7650 , s7646 and 7660 formed the first cluster. The second cluster contained 7643 and 7668. Third cluster included 7664. The separation of relatively diverse genotypes by cluster analysis as observed in the present study is compatible with finding of [10].

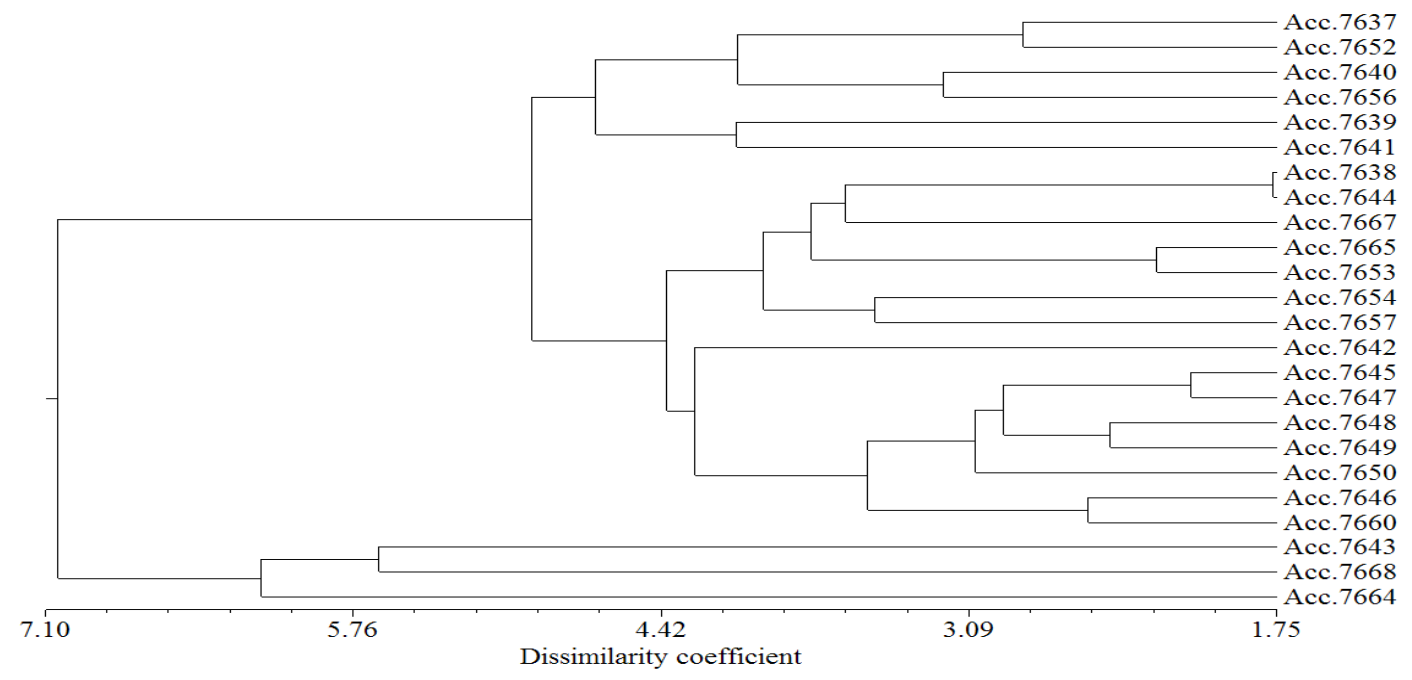

Figure 4. Dendrogram of rice accessions based on dissimilarity matrix of euclidean distances For quantitative traits 


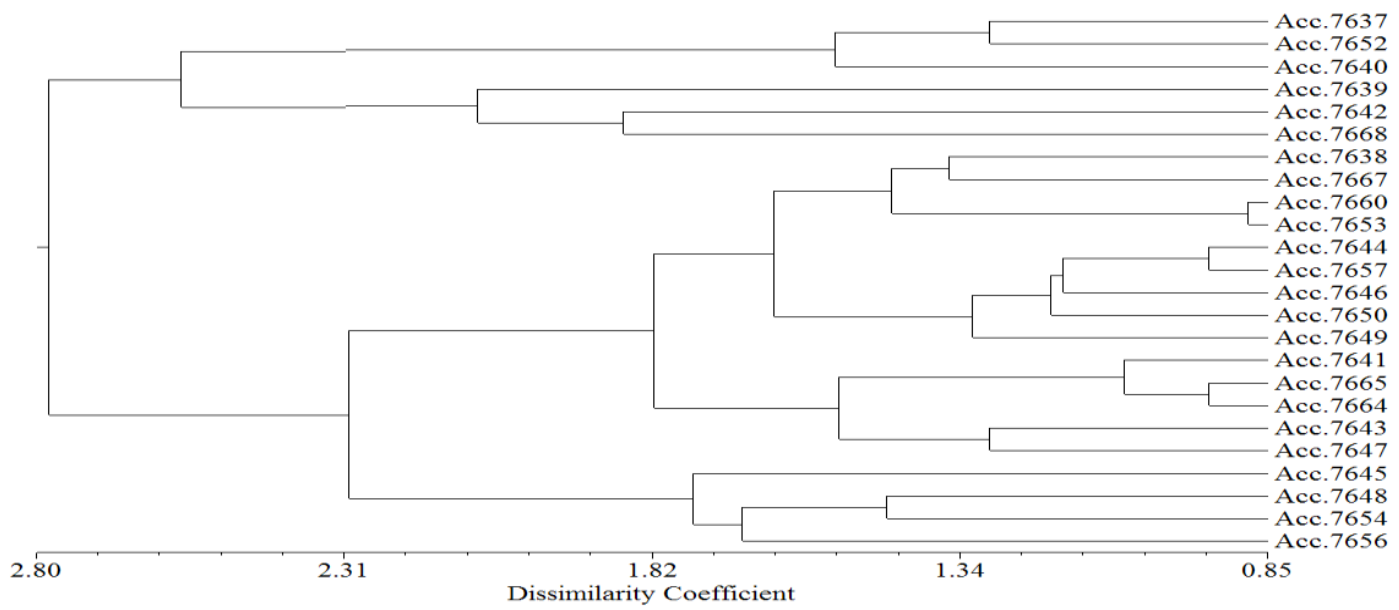

Figure 5. Dendrogram of rice accessions based on dissimilarity matrix of euclidean distances for qualitative traits

\section{Conclusion}

Cluster analysis for both qualitative and quantitative traits clearly clustered. It is concluded that rice genotype (007664) showed much variation for qualitative and quantitative traits. Further, it has batter consequences for yield components. Accession number 7639, 7665, 7649, 7652 also displayed excellence for various yield associated character and can be used in future rice breeding programs.

\section{Authors' contributions}

Conceived and designed the experiments: IH Khalil, Performed the experiments: Alia, Analyzed the data: M Noor, Contributed reagents/ materials/ analysis tools: Durrishahwar, Wrote the paper: Alia \& SMA Shah.

\section{References}

1. FAOSTAT (2008). Available at http:faostat.fao.org (accessed 15 Aug, 2009).

2. Khan MA, Bashir E \& Bantel R (2001). (Plant breeding. Ed $1^{\text {st }}$ ). National Book Foundation Islamabad.

3. Gottileb H, Bretting RS \& Weidrlechner PK (1995). Study of inheritance of certain quantitative and qualitative traits on dwarf and tall indica rice varieties (Oryza sativa L.). Madras Agric J 71: 634-639.
4. Jones RS, Kikuchi H \& Kinoshita $\mathrm{T}$ (1997). Quantitative genetic variation in isogenetic lines of Taichung 65 for marker genes. Mem Fac Agric J 15:63-67.

5. Kaul MLM, \& Kumar V (1982). Genetic variability in rice. $J$ Genetica Agraria 36(3-4):257-268.

6. Sohei KS, Takashi Y \& Sato YT (2003). Identification and characterization of quantitative trait loci affecting spikelet number per panicle in rice (Oryza sativa L.) PI Cell Phsiol 27:135-145

7. Zhang YS, Ling J, Chen L \& Wan MZ (2007). Quantitative trait loci for rice heading date in Koshihikari. J Agric Res 32:14-22.

8. Elizabeth AV, Silva EF, Schammass EA \& Oliveira GC (2008). Morphoagronomic genetic diversity in American wild rice species. Braz Arch Biol Technol (1): 94104.

9. Almasy L \& Blangero J (1999). Multipoint quantitative- trait linkage analysis in general pedigrees. Am J Hum Genet 62: 1198-1211.

10. Uga Y, Fukuta Y, Ohsawa R \& Fujimura $\mathrm{T}$ (2006). Variations of floral traits in Asian cultivated rice (Oryza sativa L.) and its wild relatives (O. rufipogon Griff). Japan Int Res Center Agri Sci (46):71-79, 89-92. 